\title{
Hydrothermal modification of carbon adsorbents
}

\author{
J. Skubiszewska-Zięba • V.V. Sydorchuk • V.M. Gun'ko • \\ R. Leboda
}

Received: 15 September 2010 / Accepted: 9 August 2011 / Published online: 3 September 2011

(C) The Author(s) 2011. This article is published with open access at Springerlink.com

\begin{abstract}
The effects of high-pressure autoclave treatments on porous structure and surface properties were studied for a variety of activated carbons (AC, synthetic and produced from plum stones) treated with water vapour, hydrogen peroxide (10-50\%) or $10 \%$ aqueous ammonia solution at relatively low temperatures $\left(250,350,400^{\circ} \mathrm{C}\right)$. Surface and structural parameters of modified ACs were determined using nitrogen, water, ammonia and benzene adsorption isotherms. It was found that the effects of AC modification resulting in changes in their porous structure and surface chemistry depend on the kind of initial ACs, modifier type and concentration of modifier and treatment temperature. At the same conditions synthetic ACs are modified to a larger extent than ACs prepared using natural raw materials. Repeated treatment of a given carbon intensifies changes in its porous structure.
\end{abstract}

Keywords Activated carbon $\cdot$ Hydrothermal treatment . Hydrogen peroxide · Porous structure · Slitshaped pores . Primary adsorption centres · Ammonia adsorption

J. Skubiszewska-Zięba $\cdot$ R. Leboda

Faculty of Chemistry, Maria Curie-Skłodowska University, Maria

Curie-Skłodowska Sq. 3, 20031 Lublin, Poland

V.V. Sydorchuk ( $\varangle)$

Institute for Sorption and Problems of Endoecology, Ukrainian National Academy of Sciences, 13 Naumov Street, 03164 Kiev, Ukraine

e-mail: bilychi@ukr.net

V.M. Gun'ko

Institute of Surface Chemistry, Ukrainian National Academy of Sciences, 17 General Naumov Street, Kiev 03164, Ukraine

\section{Introduction}

Carbon adsorbents due to their structural characteristics and physicochemical properties are widely used in many adsorption, catalytic, liquid and air purification processes (Jankowska et al. 1991a; Fenelonov 1995). These materials are inert, exhibit a high specific surface area and a large pore volume and possess high chemical and mechanical stability. However, activated carbons (ACs) are characterized by certain surface heterogeneity (Jankowska et al. 1991a; Fenelonov 1995; Tarkovskaya 1981) because of the presence of such heteroatoms as oxygen, nitrogen, hydrogen and others whose amounts vary depending on the nature of the AC precursors, and reaction, activation and modification conditions (Jankowska et al. 1991a; Tarkovskaya 1981; Marsh et al. 1997). These heteroatoms are fixed in the carbon matrix in the form of carboxyls, carbonyls, phenols, ketones, amine, amide and other functionalities (Jankowska et al. 1991a; Fenelonov 1995; Marsh et al. 1997). Their presence affects acidity/basicity of the AC surfaces (Jankowska et al. 1991b). AC interaction with adsorbates, especially selectivity of the adsorption, strongly depends on the content and type of the mentioned functionalities (Tarkovskaya 1981; Salame and Bandosz 1999; Salame et al. 1999). Oxidation of carbons is the most frequently applied method of AC surface properties modification (Jankowska et al. 1991a; Fenelonov 1995; Marsh et al. 1997). This process can be carried out in gaseous media using oxygen, ozone and nitrogen oxides or in a liquid phase using hydrogen peroxide, nitric acid, perchloric acid, potassium permanganate, and other oxidizing agents (Jankowska et al. 1991a; Fenelonov 1995).

The degree of AC oxidation and the type of created surface functionalities depends on chemical properties of oxidizing agent, oxidation temperature and time, as well as 
the chemical composition of the initial carbon materials (Jankowska et al. 1991a; Marsh et al. 1997; Gun'ko 2005; Choma et al. 1999; Moreno-Castilla et al. 1995). Small or large changes in the structural parameters of ACs depend on oxidation conditions (Jankowska et al. 1991a; Marsh et al. 1997; Gun'ko 2005; Choma et al. 1999; Moreno-Castilla et al. 1995; Gil et al. 1997). There are many methods to enhance the surface functionality of ACs (Choma et al. 1999). Despite numerous papers published on AC oxidation or other modifications, the using of new techniques can be perspective for these purposes.

This paper presents a simple way of modification of AC surface using hydrothermal high-pressure autoclave treatments (HTT). The effects of treatment conditions, kinds of modifiers and initial ACs on the surface properties and porous structure of modified ACs samples were studied. Water vapour, hydrogen peroxide of different concentration (10-50\%) and 10\% ammonia solutions were used as modifiers. The effects of modification of commercial and synthetic (prepared from organic polymers) ACs are compared. It should be noted that only few works, published earlier, were devoted to HTT of carbon materials (under suband supercritical conditions) with the purpose of modification of their porous and surface structure (Nieh and Grow 1987; Matsumura et al. 1997; Turov et al. 2002). Authors of these investigations were found the changes of porous structure parameters in hydrothermal conditions and suggested that observed changes are caused by gasification of carbon. However, indicated studies are not systematic. Particularly, it is difficult to draw general conclusions about the effect of this treatment on carbon porous structure.

\section{Experimental}

ACs produced from fruit stones A2PS (Gryskaf, Poland) and KAU (Russia) and spherical carbon with nitrogen (SCN) prepared at the Institute of Sorption and Endoecology Problems (Kiev, Ukraine) were used as carbon adsorbents. Their modification was carried out in the steam phase at autogeneous pressure of modifier. Meantime, $1 \mathrm{~g}$ AC was loaded in quartz insert that was placed into stainless-steel autoclave with volume of $45 \mathrm{ml} .15 \mathrm{ml}$ of modifier was poured on the bottom of autoclave. Distilled water, $10-50 \%$ w/w aqueous solutions of hydrogen peroxide and $10 \%$ aqueous solution of ammonia were used as modifiers. Temperature of HTT was $250,350^{\circ} \mathrm{C}$, its duration was $3 \mathrm{~h}$. Activated carbon $\mathrm{KAU}$ was also subjected to more severe HTT, namely by pure water at $400^{\circ} \mathrm{C}, 50 \% \mathrm{w} / \mathrm{w}$ aqueous solutions of hydrogen peroxide at $350^{\circ} \mathrm{C}$, and twice repeated HTT by $30 \% \mathrm{w} / \mathrm{w}_{2} \mathrm{O}_{2}$ at $350^{\circ} \mathrm{C}$. The latter variant of HTT was performed as follows: the reaction products were removed from the autoclave after the first treatment, a fresh solution of hydrogen peroxide was added to the autoclave and then $\mathrm{AC}$ was subjected to repeated treatment.

Nitrogen adsorption-desorption isotherms were recorded at $77.4 \mathrm{~K}$ using a Micromeritics ASAP 2405N (V.1.01) adsorption analyser. Adsorption of water vapour, benzene and ammonia was measured at $20^{\circ} \mathrm{C}$ using a McBain apparatus with a quartz spiral.

The specific surface area $S_{\mathrm{BET}}$ was calculated according to the standard BET method (Gregg and Sing 1982) at $p / p_{0}=0.05-0.23$ (where $p$ and $p_{0}$ denote the equilibrium and saturation pressures of nitrogen respectively). Sorption pore volume $V_{p}$ was determined from nitrogen adsorption isotherms at $p / p_{0}=1$.

Pore size distributions (PSD, $f_{\mathrm{V}}(x)$ and $f_{\mathrm{S}}(x)$ with respect to the pore volume and the specific surface area, respectively) were calculated using overall equation within the framework of Density Functional Theory (DFT) (Do et al. 2001; Platzer and Maurer 1989) The differential PSDs $f_{\mathrm{V}}(x)$ were converted to incremental PSDs (IPSD). The $f_{\mathrm{V}}(x)$ and $f_{\mathrm{S}}(x)$ functions were used to calculate contributions of micropores $\left(S_{\text {mic }}^{*}, V_{\text {mic }}\right)$ at the pore half-width $x<1 \mathrm{~nm}$, mesopores $\left(S_{\text {mes }}^{*}, V_{\text {mes }}\right)$ at $1<x<25 \mathrm{~nm}$, and macropores $\left(S^{*}{ }_{\text {mac }}, V_{\mathrm{mac}}\right)$ at $25<x<100 \mathrm{~nm}$ to the specific surface area and the total porosity. Additionally, $f_{\mathrm{S}}(x)$ was used to estimate deviation of the pore shape from the model of slitshaped pores (Platzer and Maurer 1993)

$\Delta w=\frac{S_{\mathrm{BET}}}{\int_{x_{\min }}^{x_{\max }} f_{S}(x) d x}-1$

where $x_{\max }$ and $x_{\min }$ are the maximal and minimal pore half-widths respectively. The $S_{\mathrm{mic}}^{*}, S_{\mathrm{mes}}^{*}$ and $S_{\mathrm{mac}}^{*}$ values were corrected by multiplication by $(\Delta w+1)$ that gives $S^{*}(\Delta w+1)=S_{\mathrm{sum}}=S_{\mathrm{mic}}+S_{\mathrm{mes}}+S_{\mathrm{mac}}=S_{\mathrm{BET}}$.

The distribution functions $f(\Delta G)$ of Gibbs free energy $(\Delta G)$ of adsorption of water and benzene were calculated using the Langmuir equation (Gregg and Sing 1982)

$\Theta=\frac{b c}{1+b c}$,

(where $b=e^{-\frac{\Delta G+z}{R_{g} T}}, c=p / p_{0}$ is the relative pressure; and $R_{g}$ is the gas constant, having regard to lateral interactions $(z)$ between adsorbed molecules assuming $z=3 / 2 R_{g} T$ ) as the kernel in the overall adsorption equation in the form of Fredholm integral equation of the first kind

$\Theta\left(T, C_{e q}\right)=\int_{\Delta G_{\min }}^{\Delta G_{\max }} \Theta_{l}\left(T, C_{e q}, \Delta G\right) f(\Delta G) d(\Delta G)$.

Equation (3) was solved using a regularization procedure under the nonnegativity condition $(f(\Delta G)>0$ at any $\Delta G$ values) and the fixed regularization parameter $\alpha=0.01$. Equation (3) was also used to calculate the distribution 
Table 1 Structural characteristics of A2PS samples

\begin{tabular}{|c|c|c|c|c|c|c|c|c|c|c|}
\hline Sample & Treatment condition & $\begin{array}{l}S_{\mathrm{BET}} \\
\mathrm{m}^{2} / \mathrm{g}\end{array}$ & $\begin{array}{l}S_{\mathrm{mic}} \\
\mathrm{m}^{2} / \mathrm{g}\end{array}$ & $\begin{array}{l}S_{\text {mes }} \\
\mathrm{m}^{2} / \mathrm{g}\end{array}$ & $\begin{array}{l}S_{\mathrm{mac}} \\
\mathrm{m}^{2} / \mathrm{g}\end{array}$ & $\begin{array}{l}V_{p} \\
\mathrm{~cm}^{3} / \mathrm{g}\end{array}$ & $\begin{array}{l}V_{\text {mic }} \\
\mathrm{cm}^{3} / \mathrm{g}\end{array}$ & $\begin{array}{l}V_{\text {mes }} \\
\mathrm{cm}^{3} / \mathrm{g}\end{array}$ & $\begin{array}{l}V_{\mathrm{mac}} \\
\mathrm{cm}^{3} / \mathrm{g}\end{array}$ & $\Delta w_{\text {slit }}$ \\
\hline A2PS-0 & & 1054 & 930 & 121 & 3 & 0.940 & 0.468 & 0.258 & 0.213 & 0.239 \\
\hline A2PS-1 & Water, $250^{\circ} \mathrm{C}$ & 1080 & 975 & 101 & 4 & 0.969 & 0.508 & 0.246 & 0.215 & 0.128 \\
\hline A2PS-2 & Water, $350^{\circ} \mathrm{C}$ & 1019 & 927 & 90 & 3 & 0.837 & 0.465 & 0.185 & 0.187 & 0.184 \\
\hline A2PS-3 & $10 \% \mathrm{H}_{2} \mathrm{O}_{2}, 250^{\circ} \mathrm{C}$ & 1021 & 905 & 113 & 3 & 0.831 & 0.441 & 0.203 & 0.187 & 0.261 \\
\hline A2PS-4 & $10 \% \mathrm{NH}_{3}, 250^{\circ} \mathrm{C}$ & 960 & 874 & 83 & 3 & 0.791 & 0.462 & 0.178 & 0.151 & 0.128 \\
\hline A2PS-5 & $20 \% \mathrm{H}_{2} \mathrm{O}_{2}, 250^{\circ} \mathrm{C}$ & 994 & 873 & 116 & 6 & 0.961 & 0.443 & 0.246 & 0.272 & 0.108 \\
\hline A2PS-6 & $30 \% \mathrm{H}_{2} \mathrm{O}_{2}, 250^{\circ} \mathrm{C}$ & 933 & 843 & 86 & 4 & 0.767 & 0.418 & 0.209 & 0.141 & 0.131 \\
\hline A2PS-7 & $30 \% \mathrm{H}_{2} \mathrm{O}_{2}, 350^{\circ} \mathrm{C}$ & 1042 & 953 & 86 & 3 & 0.742 & 0.430 & 0.153 & 0.159 & 0.274 \\
\hline
\end{tabular}

functions of nitrogen adsorption energy using the FowlerGuggenheim equation (describing localized monolayer adsorption with lateral interaction) (Gun'ko and Mikhalovsky 2004) as the kernel.

Concentration of primary adsorption centres (PAC) was calculated from the water vapour adsorption data using Dubinin-Sierpinsky equation (Dubinin and Sierpinsky 1981). Geometrical surface $S_{g}$ (Dubinin's term) of activated carbon SCN was also determined from isotherms of water vapour (Dubinin and Sierpinsky 1981).

\section{Results and discussion}

There are not clear relationships between conditions of carbon A2PS treatment and changes in the structural characteristics of the samples (Table 1); however, certain tendencies can be found. For instance, the treatment of A2PS with water vapour at $250^{\circ} \mathrm{C}$ results in slight increase of the specific surface area due to development of microporosity, since a small raise in the $S_{\text {mic }}, V_{\text {mic }}$, and $V_{p}$ values but insignificant changes in other structural characteristics is observed. It should be noted that increase both of specific surface area and microporosity as a result of treatment by supercritical water $\left(600^{\circ} \mathrm{C}, 34.5 \mathrm{MPa}\right)$ was earlier observed (Matsumura et al. 1997). Elevation of temperature to $350^{\circ} \mathrm{C}$, on contrary, leads to some reduction of $S_{\mathrm{BET}}$ and $V_{p}$ which, obviously, occurs owing to partial destruction of mesopores $\left(S_{\text {mes }}\right.$ decreases from 121 to $90 \mathrm{~m}^{2} / \mathrm{g}$ and $V_{\text {mes }}$ lowers from 0.26 to $0.19 \mathrm{~cm}^{3} / \mathrm{g}$ ).

At the same time, hydrothermal modification of A2PS with $\mathrm{H}_{2} \mathrm{O}_{2}$ causes a decrease in all structural characteristics. Meantime, the higher concentration of $\mathrm{H}_{2} \mathrm{O}_{2}$ is, the greater effect HTT at $250^{\circ} \mathrm{C}$ causes. Thus, $S_{\text {BET }}$ and $V_{p}$ reduce in 11.5 and $18.0 \%$, respectively, when concentration of $\mathrm{H}_{2} \mathrm{O}_{2}$ grows to $30 \%$. Observed lowering of $S_{\mathrm{BET}}$ and $V_{p}$ can be explained by changes both in micro- and mesoporous structure of carbon, namely breaking (through burning of carbon) of pores walls. The treatment with the ammonia solution leads to a reduction of the porosity, and it is bigger than that after the treatment with $10 \% \mathrm{H}_{2} \mathrm{O}_{2}$ solution. This unexpected result may be due to the fact that carbon dioxide, released during the oxidation of carbon, is bonded with ammonia. Therefore, the equilibrium of process shifts toward the reaction products, i.e. oxidation occurs more deeply. However, nitrogen is not incorporated in the structure of carbon. The latter is confirmed by elemental analysis (Hereaus $\mathrm{CNH}$ analyzer).

On the other hand, modification with $30 \%$ hydrogen peroxide solution at $350^{\circ} \mathrm{C}$ causes certain development of microporosity $\left(S_{\text {mic }}, V_{\text {mic }}\right)$ and macroporosity $\left(V_{\text {mac }}\right)$, but decrease in the $S_{\mathrm{BET}}$ value and contribution of mesopores $\left(V_{\text {mes }}\right)$ in comparison those for A2PS treated with $30 \%$ $\mathrm{H}_{2} \mathrm{O}_{2}$ at $250^{\circ} \mathrm{C}$. At the same time, comparison of porous structure parameters for these modified samples with those for initial A2PS indicates that effect of HTT is minimal. The latter can be associated with inhibition of modification (oxidation) process by gaseous reaction products.

Activated carbon KAU, which is similar to A2PS, has stone fruit origin, was subjected to the same HTT. Besides, other procedures of modification were used, namely double HTT with $30 \% \mathrm{H}_{2} \mathrm{O}_{2}$ and HTT with $50 \% \mathrm{H}_{2} \mathrm{O}_{2}$. Table 2 presents some of obtained results. As can be seen, double HTT causes greater decrease of all porous structure parameters, except $V_{\text {mes }}$, compared with single HTT. Even more significant reduction in porosity is observed as a result of HTT with $50 \%$ hydrogen peroxide solution, although the volume of mesopores increases in this case. Obviously, part of micropores transforms into mesopores using HTT by high-concentrated $\mathrm{H}_{2} \mathrm{O}_{2}$.

The KAU treatment with pure water at $400^{\circ} \mathrm{C}$ increases contribution of micropores to the surface area (Table 2, $S_{\text {mic }}$ ); however, the $V_{p}$ and $S_{\text {BET }}$ values decrease.

The third studied carbon SCN has poorly developed porosity determined from adsorption of nitrogen (Table 3, SCN-0); therefore, one can expect that HTT modification of SCN can give rather positive structural changes. The treatment of $\mathrm{SCN}$ with water vapour at $250^{\circ} \mathrm{C}$ does 
Table 2 Structural

characteristic of KAU samples

\begin{tabular}{llllllll}
\hline Sample & Treatment condition & $\begin{array}{l}S_{\text {BET }}, \\
\mathrm{m}^{2} / \mathrm{g}\end{array}$ & $\begin{array}{l}S_{\text {mic }}, \\
\mathrm{m}^{2} / \mathrm{g}\end{array}$ & $\begin{array}{l}V_{p}, \\
\mathrm{~cm}^{3} / \mathrm{g}\end{array}$ & $\begin{array}{l}V_{\text {mic }}, \\
\mathrm{cm}^{3} / \mathrm{g}\end{array}$ & $\begin{array}{l}V_{\text {mes }}, \\
\mathrm{cm}^{3} / \mathrm{g}\end{array}$ & $\Delta w_{\text {slit }}$ \\
\hline $\mathrm{KAU}-0$ & Initial & 952 & 796 & 0.51 & 0.33 & 0.15 & 0.053 \\
$\mathrm{KAU}-1$ & $\mathrm{HTT} \mathrm{H}_{2} \mathrm{O}, 400^{\circ} \mathrm{C}$ & 944 & 803 & 0.48 & 0.33 & 0.12 & 0.041 \\
$\mathrm{KAU}-2$ & Single HTT 30\% $\mathrm{H}_{2} \mathrm{O}_{2}, 350^{\circ} \mathrm{C}$ & 973 & 662 & 0.54 & 0.28 & 0.16 & 0.125 \\
$\mathrm{KAU}-3$ & Double HTT 30\% $\mathrm{H}_{2} \mathrm{O}_{2}, 350^{\circ} \mathrm{C}$ & 725 & 436 & 0.46 & 0.21 & 0.16 & 0.213 \\
$\mathrm{KAU}-4$ & Single HTT 50\% $\mathrm{H}_{2} \mathrm{O}_{2}, 350^{\circ} \mathrm{C}$ & 706 & 336 & 0.39 & 0.15 & 0.24 & 0.022 \\
\hline
\end{tabular}

Table 3 Structural characteristics of SCN samples

\begin{tabular}{|c|c|c|c|c|c|c|c|c|c|c|c|}
\hline Sample & Treatment condition & $\begin{array}{l}S_{g}, \\
\mathbf{m}^{2} / \mathbf{g}\end{array}$ & $\begin{array}{l}S_{\mathrm{BET}} \\
\mathrm{m}^{2} / \mathrm{g}\end{array}$ & $\begin{array}{l}S_{\mathrm{mic}} \\
\mathrm{m}^{2} / \mathrm{g}\end{array}$ & $\begin{array}{l}S_{\text {mes }} \\
\mathrm{m}^{2} / \mathrm{g}\end{array}$ & $\begin{array}{l}S_{\mathrm{mac}} \\
\mathrm{m}^{2} / \mathrm{g}\end{array}$ & $\begin{array}{l}V_{p} \\
\mathrm{~cm}^{3} / \mathrm{g}\end{array}$ & $\begin{array}{l}V_{\text {mic }} \\
\mathrm{cm}^{3} / \mathrm{g}\end{array}$ & $\begin{array}{l}V_{\text {mes }} \\
\mathrm{cm}^{3} / \mathrm{g}\end{array}$ & $\begin{array}{l}V_{\mathrm{mac}} \\
\mathrm{cm}^{3} / \mathrm{g}\end{array}$ & $\Delta w_{\text {slit }}$ \\
\hline 1 & 2 & 3 & 4 & 5 & 6 & 7 & 8 & 9 & 10 & 11 & 12 \\
\hline SCN-0 & & 422 & 192 & 175 & 14 & 3 & 0.305 & 0.099 & 0.108 & 0.098 & 0.014 \\
\hline SCN-1 & Water, $250^{\circ} \mathrm{C}$ & 435 & 191 & 171 & 16 & 5 & 0.407 & 0.111 & 0.124 & 0.173 & 0.064 \\
\hline SCN-2 & $10 \% \mathrm{H}_{2} \mathrm{O}_{2}, 250^{\circ} \mathrm{C}$ & 569 & 461 & 437 & 20 & 5 & 0.626 & 0.222 & 0.129 & 0.275 & -0.055 \\
\hline $\mathrm{SCN}-3$ & $10 \% \mathrm{NH}_{3}, 250^{\circ} \mathrm{C}$ & 425 & 173 & 152 & 17 & 4 & 0.423 & 0.096 & 0.156 & 0.170 & -0.063 \\
\hline SCN-4 & Water, $350^{\circ} \mathrm{C}$ & 455 & 295 & 280 & 12 & 4 & 0.461 & 0.157 & 0.110 & 0.194 & -0.110 \\
\hline SCN-5 & $20 \% \mathrm{H}_{2} \mathrm{O}_{2}, 250^{\circ} \mathrm{C}$ & 523 & 345 & 322 & 17 & 6 & 0.659 & 0.185 & 0.160 & 0.313 & 0.008 \\
\hline SCN-6 & $30 \% \mathrm{H}_{2} \mathrm{O}_{2}, 250^{\circ} \mathrm{C}$ & 494 & 186 & 161 & 23 & 7 & 0.572 & 0.087 & 0.145 & 0.340 & 0.276 \\
\hline SCN-7 & $30 \% \mathrm{H}_{2} \mathrm{O}_{2}, 350^{\circ} \mathrm{C}$ & 481 & 297 & 279 & 15 & 3 & 0.459 & 0.153 & 0.147 & 0.159 & -0.071 \\
\hline
\end{tabular}

not practically change the specific surface area of different pores (Table 3, S) but causes increase in the porosity $\left(V_{p}, V_{\mathrm{mes}}, V_{\mathrm{mac}}\right)$. However, elevation of HTT temperature by $100^{\circ} \mathrm{C}$ results in significant increase in both types of structural parameters (specific surface area and pore volume). Hydrogen peroxide solution more strongly affects the structural parameters of SCN. The $10 \% \mathrm{H}_{2} \mathrm{O}_{2}$ solution at $250^{\circ} \mathrm{C}$ gives significant increase in the $S_{\mathrm{BET}}$ and $S_{\text {mic }}$ as well as $V_{p}, V_{\text {mic }}, V_{\text {mac }}$ values (Table 3 ). Meantime $S_{\mathrm{BET}}$ increases by almost two and a half times, and $V_{p}$ grows more than twice. With increasing $\mathrm{H}_{2} \mathrm{O}_{2}$ concentration the porosity, especially macroporosity, rises but the surface area drops down. Changes in the porous structure of SCN treated with $10 \%$ ammonia resemble that obtained for A2PS treated in the same conditions.

It should be noted that actual increase both of specific surface area $S_{\mathrm{BET}}$ and sorption pore volume $V_{p}$ observed during HTT of SCN may be not so. Indeed, comparison of $S_{\mathrm{BET}}$ with the corresponding values of $S_{g}$, calculated from the adsorption isotherms of water vapor (columns 3 and 4 of Table 3), confirms this assumption. This can be explained by the fact that the lowered $S_{B E T}$ and $V_{p}$ values were obtained for samples with the smallest pores (including initial) using low-temperature measurements of nitrogen adsorption. Obviously, the smallest pores are inaccessible for nitrogen molecules in these conditions. At the same time, smaller molecules of water penetrate into these pores at $20^{\circ} \mathrm{C}$. Therefore, $S_{g}$ is greater than $S_{\mathrm{BET}}$ for all samples and ratio $S_{g} / S_{\mathrm{BET}}$ can indicate fraction of the smallest pores in sample. However, general trend of changes in specific surface area with increasing of HTT temperature and hydrogen peroxide concentration is preserved when the value $S_{g}$ is used. Thus, $S_{g}$ grows in 1.4 times as a result of HTT of SCN at $250^{\circ} \mathrm{C}$ with $10 \% \mathrm{H}_{2} \mathrm{O}_{2}$ solution while $S_{\mathrm{BET}}$ of this sample exceeds that for initial SCN in 2.4 times. In our opinion, value of $S_{g} / S_{\mathrm{BET}}$ indicate fraction of the smallest pores in SCN samples.

Analysis of the PSDs for three series of treated carbons calculated from adsorption-desorption of nitrogen (Figs. 13) shows that changes are much more significant for treated SCN samples (Fig. 3) than those for A2PS (Fig. 1) or KAU (Fig. 2). Initial A2PS (A2PS-0) as a carbon produced from a natural raw material (plum stones) has a relatively large $\Delta w$ value. This reveals that the shape of pores does not exactly correspond to ideally slitshaped pores. Treatment with water at $250^{\circ} \mathrm{C}$ (A2PS-1) leads to structure of pores which is more close to slitshaped because of the removal of ash nanoparticles and other defective fragments which are more hydrophilic than ideal basal planes responsible for the slitshaped porosity of the material; however, the PSD changes are insignificantly (Fig. 1). An increase in the HTT temperature to $350^{\circ} \mathrm{C}$ sligthly enhances nonideality of the pore shape and changes in the PSD become more significant.

Modification of A2PS with $\mathrm{H}_{2} \mathrm{O}_{2}$ or $\mathrm{NH}_{3}$, leads to certain decomposition of the pore walls because the pore volume and the specific surface area decrease in comparison 
Fig. 1 DFT pore size

distributions with respect to (a) the pore volume and (b) the specific surface area for treated A2PS samples (carbon numbers are from Table 1)
Fig. 2 IPSD for treated carbons KAU (a) calculated using Quantachrome DFT software and (b) another DFT approach (Platzer and Maurer 1993) (carbon numbers are from Table 2) (a)

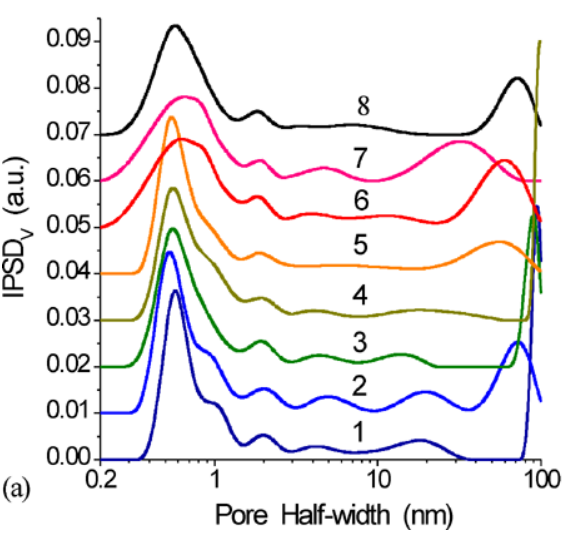

(b)
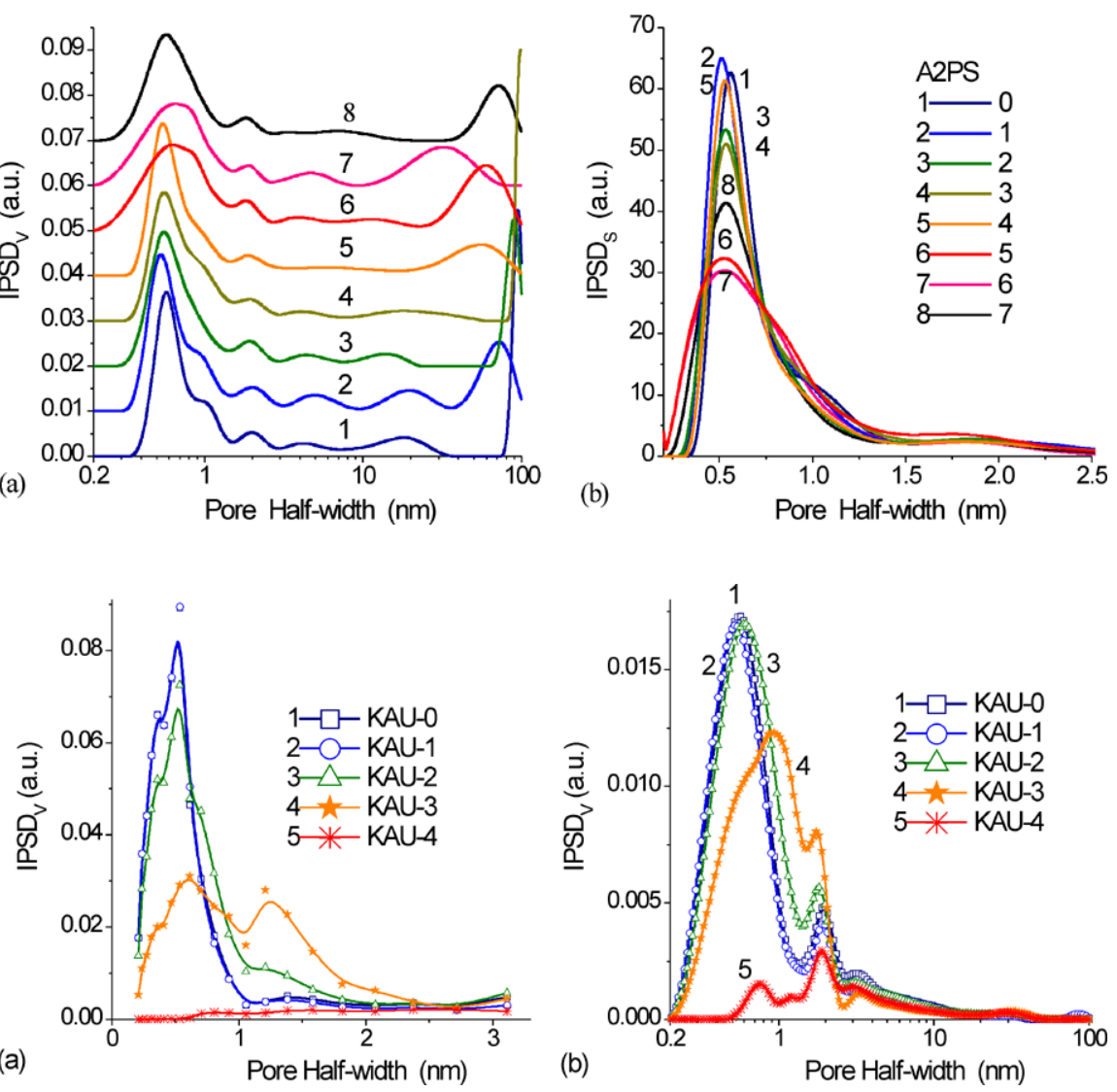

Fig. 3 PSDs calculated using DFT with the model of slitshaped pores for treated carbon SCN samples (carbon numbers are from Table 3 )

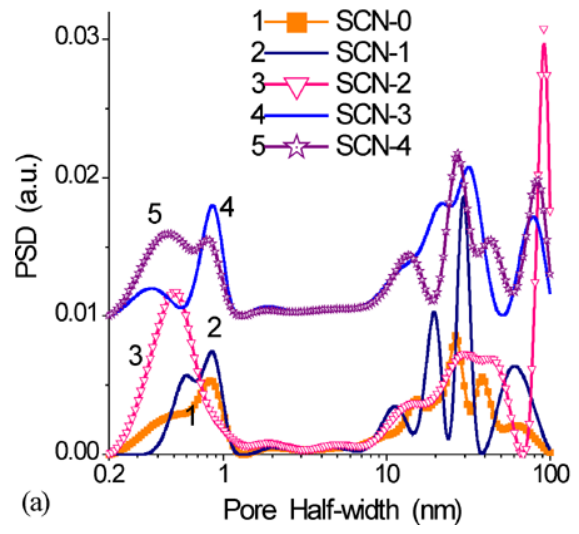

with the initial A2PS. Some redistribution of different type of pores occurs, as a result. The character and the extent of these structural changes depend on treatment conditions (temperature and concentration of $\mathrm{H}_{2} \mathrm{O}_{2}$ or $\mathrm{NH}_{3}$ ). Clearly, the maximal changes in the structure of pore walls occur at the maximal temperature and the maximal $\mathrm{H}_{2} \mathrm{O}_{2}$ concentration (Fig. 1) that give the maximal $\Delta w$ value. In other words, the treatment leads initially to the improved pore structure ( $\Delta w$ decreases) but than the nonideality of the pore shape grows ( $\Delta w$ increases) because partial decomposition of the pore walls occurs. Similar but slightly more significant (because of higher temperature or greater concentration of
$\mathrm{H}_{2} \mathrm{O}_{2}$ ) changes are characteristic for treated KAU (Fig. 2) than that for A2PS (Fig. 1). Large changes in the structural characteristics of treated KAU samples cause significant changes in the energetic characteristics of the nitrogen adsorption (Fig. 4). Maximum diminution of the adsorption potential and adsorption energy is observed for KAU treated with $50 \% \mathrm{H}_{2} \mathrm{O}_{2}$ at $350^{\circ} \mathrm{C}$ (single HTT). Therefore, negative changes, i.e. resulting in decrease of specific surface area and sorption pore volume, take place during of A2PS and KAU HTT.

The initial SCN material produced from the polymer precursor has pore shape which is more close to ideal slitshaped 
Fig. 4 The distribution functions of nitrogen adsorption (a) potential and (b) energy for treated KAU samples
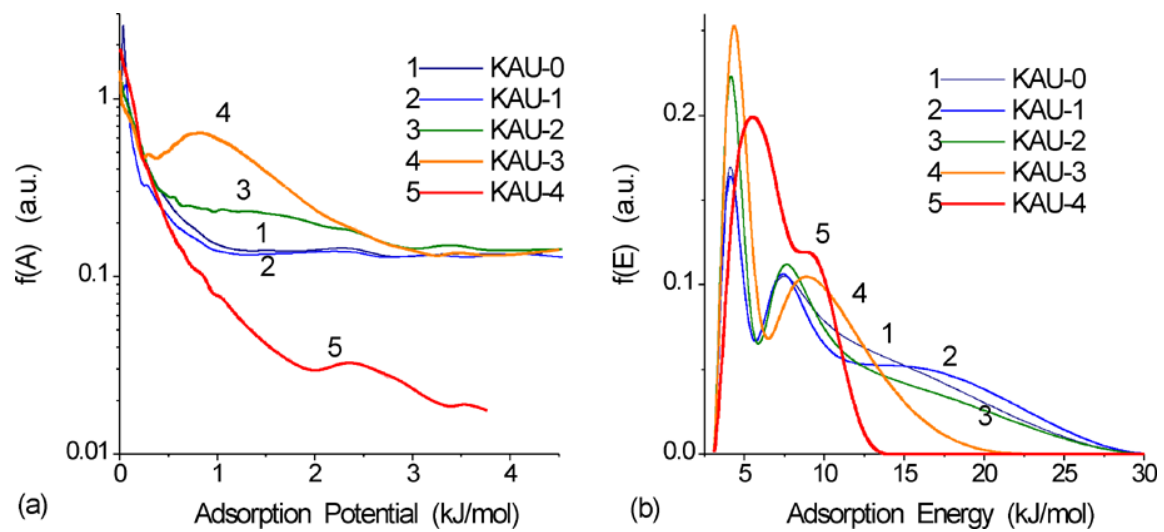

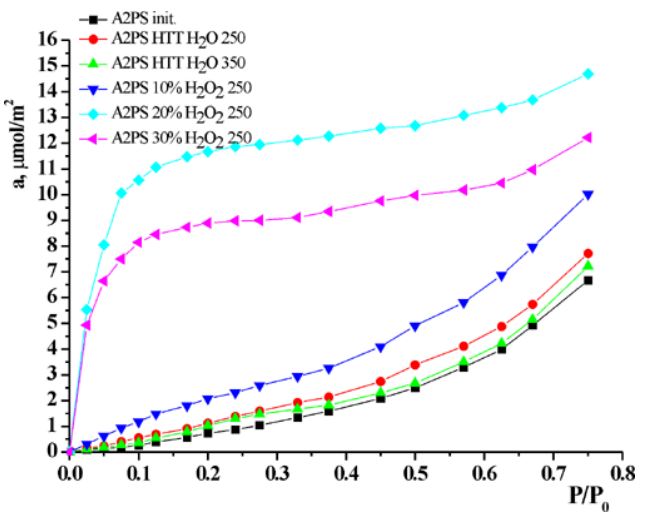

Fig. 5 The absolute adsorption isotherms of water vapour at $20^{\circ} \mathrm{C}$ on adsorbents prepared based on the carbon A2PS

pores in comparison with fruit stone based A2PS or KAU because the deviation for the initial SCN corresponds to only $1.4 \%$ and the $\Delta w$ values are typically smaller for the treated SCN samples (Table 3) than that for the treated A2PS (Table 1) and KAU (Table 2) samples. However, tendencies in changes in the pore shape of SCN differ from those for A2PS and KAU. For instance, for certain SCN samples the $\Delta w$ values are negative in contrast to A2PS or KAU. This effect can be caused by enhanced contribution of the outer surface of treated carbon granules that is much more significant for SCN with low surface area than A2PS or KAU with much higher specific surface area.

The adsorption of nitrogen onto carbons is mainly due to nonspecific interactions; however, specific interactions on adsorption of polar, aromatic and other adsorbates can play a very important role on the practical applications of carbon adsorbents. Therefore, the adsorption of water, ammonia and benzene onto studied carbons can give useful information about the treatment effects on the adsorption properties of treated carbons.

Figure 5 presents the absolute adsorption isotherms of water vapour onto some treated A2PS samples. The mechanism of water adsorption onto carbon adsorbents was proposed by Dubinin and Sierpinsky (Dubinin and Sierpinsky
Table 4 Influence of HTT on primary active centres concentration $\mu$ $\left(\mu \mathrm{mol} / \mathrm{m}^{2}\right)$ for different $\mathrm{ACs}$

\begin{tabular}{lll}
\hline Conditions of HTT & A2PS & SCN \\
\hline Initial & 0.60 & 0.37 \\
$250^{\circ} \mathrm{C} \mathrm{H} \mathrm{H}_{2} \mathrm{O}$ & 0.69 & 0.38 \\
$250^{\circ} \mathrm{C} 10 \% \mathrm{H}_{2} \mathrm{O}_{2}$ & 0.79 & 0.40 \\
$250^{\circ} \mathrm{C} 20 \% \mathrm{H}_{2} \mathrm{O}_{2}$ & 2.02 & 1.70 \\
$250^{\circ} \mathrm{C} 30 \% \mathrm{H}_{2} \mathrm{O}_{2}$ & 3.89 & 3.16 \\
$250^{\circ} \mathrm{C} 10 \% \mathrm{NH}_{3}$ & 0.56 & 0.42 \\
$350^{\circ} \mathrm{C} \mathrm{H}_{2} \mathrm{O}$ & 0.79 & 0.64 \\
$350^{\circ} \mathrm{C} 30 \% \mathrm{H}_{2} \mathrm{O}_{2}$ & 1.20 & 1.40 \\
\hline
\end{tabular}

1981). According to them, water molecules are first adsorbed on primary adsorption centres $(P A C)$ with oxygencontaining surface functionalities and then adsorption occurs on secondary sites with adsorbed water molecules. An increase in the water vapour pressure leads to the formation of clusters of associated water molecules via the hydrogen bonding (Salame and Bandosz 1999; Salame et al. 1999; Gun'ko 2005; Choma et al. 1999). The isotherms obtained for the initial A2PS as well as for the water-treated samples can be assigned to type III of the IUPAC classification (Sing et al. 1985) that is characteristic for weak adsorbent-adsorbate interactions. Water molecules interact weakly with the carbon surface due to a small number of primary active centres corresponding to $0.60,0.69$ and $0.79 \mu \mathrm{mol} / \mathrm{m}^{2}$ (Fig. 5, Table 4). These values were calculated using the DS equation (Dubinin and Sierpinsky 1981). The modification of A2PS with hydrogen peroxide causes a significant increase in the adsorption capacity compared with that for A2PS treated with water vapour (Fig. 5). Additionally, the isotherm shape for the former modified with 20 and $30 \% \mathrm{H}_{2} \mathrm{O}_{2}$ changes significantly (isotherms transform into type I of the IUPAC classification) because of an increase in the amounts of primary adsorption sites: 0.79 (Fig. 5, curve 4), 2.02 (5) and $3.89 \mu \mathrm{mol} / \mathrm{m}^{2}$ (6). Content of PAC for initial and treated SCN samples is also presented in Table 4. It can be seen that value of PAC, expressed in 


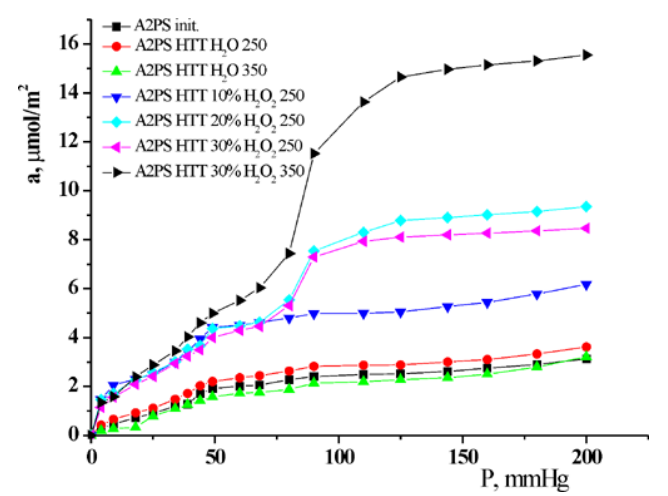

Fig. 6 The absolute adsorption isotherms of ammonia at $20^{\circ} \mathrm{C}$ on adsorbents prepared based on the carbon A2PS

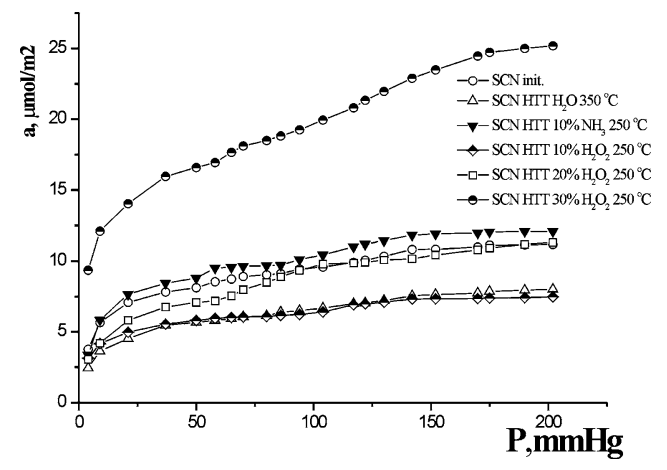

Fig. 7 The adsorption isotherms of ammonia recorded at $20^{\circ} \mathrm{C}$ on SCN samples

$\mu \mathrm{mol} / \mathrm{m}^{2}$, increases sharply with elevation of $\mathrm{H}_{2} \mathrm{O}_{2}$ concentration at $250^{\circ} \mathrm{C}$ while that considerably reduces at $350^{\circ} \mathrm{C}$ for both ACs.

As it could be expected, hydrothermal treatment of A2PS with hydrogen peroxide causes a significant increase in the adsorption of ammonia (Fig. 6) because of an increase in the number of acidic surface sites (Tomaszewski et al. 2005; Seredych and Bandosz 2007a; Seredych and Bandosz 2007b). The amounts of these groups increase much more significantly on the carbon treated with hydrogen peroxide than with water (Fig. 6). The course of isotherms obtained for SCN is similar (Fig. 7). (It should be noted that calculation of absolute isotherms for this AC is based on values of $S_{g}$ rather than $S_{\mathrm{BET}}$.) The stepped shape of the isotherm course (Figs. 6 and 7) can be due to structural and energetic heterogeneity of the samples.

The adsorbent heterogeneity can be analyzed on the basis of the distribution functions of Gibbs free energy of adsorption $f(\Delta G)$ (Fig. 8). The $f(\Delta G)$ distributions for benzene and water depend on both textural and chemical characteristics of initial and treated carbons. The structural changes in the treated A2PS and SCN carbons are rather opposite (Tables 1 and 3). Therefore a $f(\Delta G)$ peak at small $\Delta G=-1.5 \mathrm{~kJ} / \mathrm{mol}$ is observed on the adsorption of benzene onto initial SCN but it is absent for the treated SCN samples, as well as for A2PS. As it is known (Salame and Bandosz 1999) the adsorption of benzene is sensitive to the presence of surface functionalities. The differences in the minimal and maximal $-\Delta G$ values are relatively small because the samples were modified under mild conditions. In the case of water, only the differences in maximal adsorption energies are found (Fig. 8). Generally, the modified samples are more heterogeneous in relation to benzene than water. This is evidenced by the differences between the minimal and maximal energies which are much larger for benzene than for water. Independent on the kind of initial carbon this difference is about $10-12 \mathrm{~kJ} / \mathrm{mol}$ for benzene and $6-8 \mathrm{~kJ} / \mathrm{mol}$ for water. Hydrothermal modification of A2PS and SCN reduces their energetic heterogeneity to some extent. This kind of treatment was earlier applied to change the AC surface chemistry but at minimal change in the porous structure (Tomaszewski et al. 2005) that allowed studying the effect of chemical heterogeneity of the AC surface on the mechanism of amphetamines adsorption. It was found that only a portion of the surface of oxidized carbons was accessible for the adsorbed probe compounds. The Ocontaining functionalities in the vicinity of entry into narrow pores made it difficult or even impossible for explosive substances-nitroaromatic compounds (Leboda et al. 2002) to locate in such pores due to strong specific interactions (Rodriguez-Reinoso et al. 1992). It is quite possible that such effects determine the shape and course of energy distribution functions (Fig. 8).

\section{Conclusions}

The hydrothermal modification of porous structure and surface properties for activated carbons was studied at relatively low temperatures $\left(250-400^{\circ} \mathrm{C}\right)$. The modification effects related to changes in structural parameters and surface chemistry depend on the kind of a modifier $\left(\mathrm{H}_{2} \mathrm{O}\right.$ vapour, $\mathrm{H}_{2} \mathrm{O}_{2}$ or $\mathrm{NH}_{3}$ solutions), nature of carbon adsorbent and treatment temperature. Modification with water, hydrogen peroxide and ammonia under studied HTT conditions causes negative changes, as a rule, i.e. reduction in the specific surface area and the pore volume from a few to 25 percent in the case of carbons prepared from fruit stones (A2PS, KAU) and characterized by $S_{\mathrm{BET}} \approx 1000 \mathrm{~m}^{2} / \mathrm{g}$ and $V_{p}=0.5-$ $1.0 \mathrm{~cm}^{3} / \mathrm{g}$. Meanwhile, destruction of porous network due to burning of carbon of pore walls, especially as result of $\mathrm{H}_{2} \mathrm{O}_{2}$ concentration increase, is observed. The latter leads to diminution of specific surface area and pore volume for micro- and mesopores and increase of nonideality of the pore shape. Maximal changes are characteristic for KAU samples subjected to double HTT and HTT with 50\% hydrogen peroxide. HTT under these conditions also promotes transformation of part of micropores into mesopores. Thus, 
Fig. 8 The distribution functions $f(\Delta G)$ of Gibbs free energy $(\Delta G)$ of adsorption of (a), (b) benzene and (c), (d) water onto activated carbons (a), (c) A2PS and (b), (d) SCN differently treated
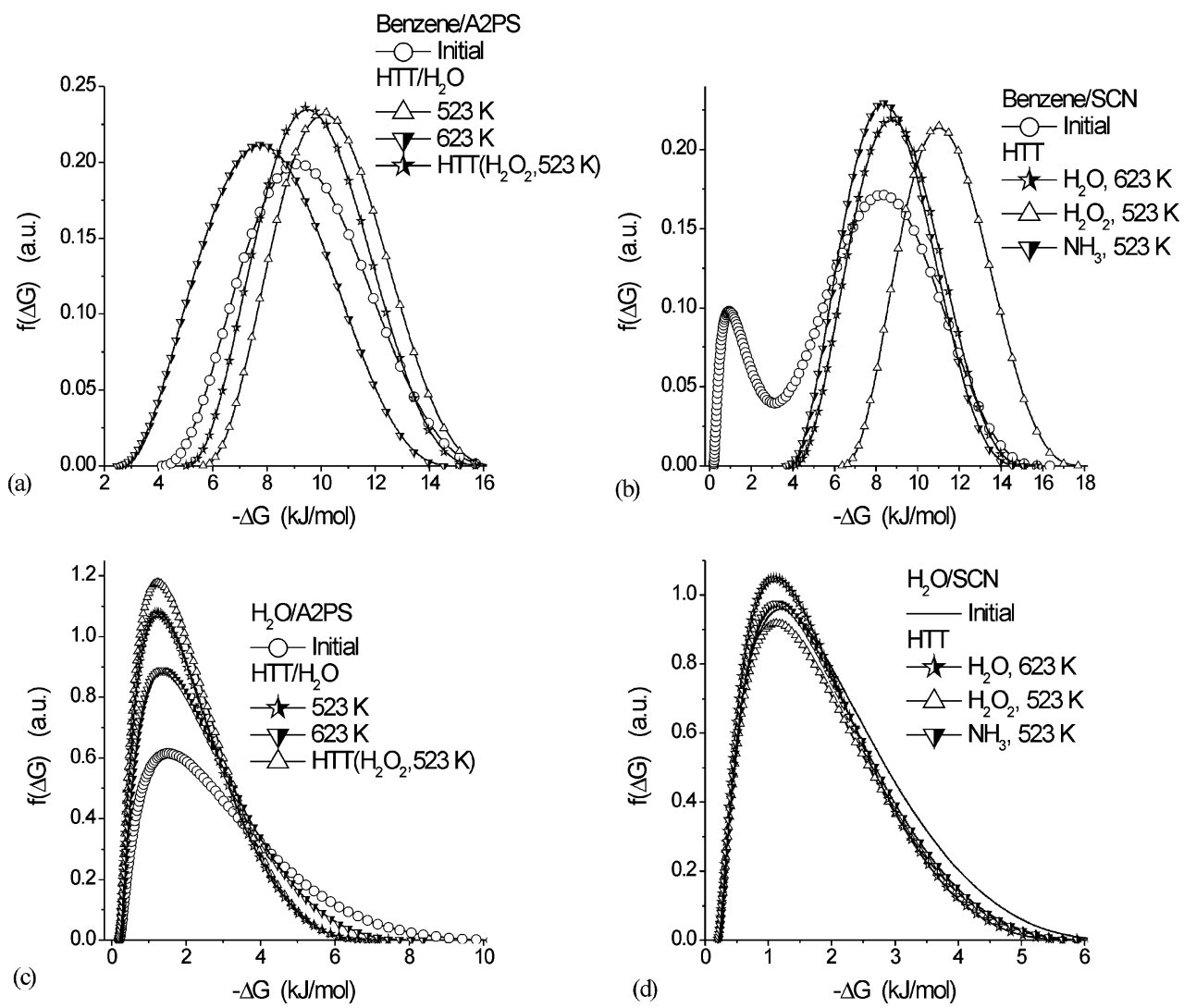

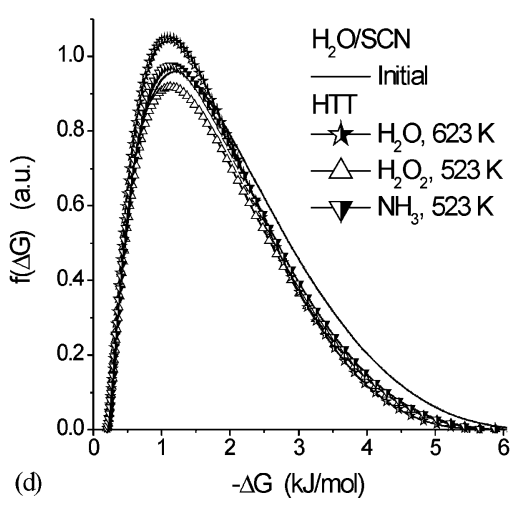

fraction of mesopores in the initial sample is about $30 \%$ whereas that for sample, modified with $50 \% \mathrm{H}_{2} \mathrm{O}_{2}$, equals more than $60 \%$, i.e. increases in 2 times.

The changes are much larger and mainly positive for carbon SCN characterized by much smaller $S_{\mathrm{BET}} \approx 200 \mathrm{~m}^{2} / \mathrm{g}$ and $V_{p} \approx 0.3 \mathrm{~cm}^{3} / \mathrm{g}$ i.e. HTT of this AC causes its activation since specific surface area $S_{\mathrm{BET}}$ and pore volume increase more than in 2 times. At the same time, the magnitude of this effect is not so great if the data of adsorption of water are used for calculation of specific surface area (geometrical surface determined from water vapour adsorption increases in 1.35 times). In other words, the value of effect is determined by the accessibility of pores for the molecules of adsorbate.

HTT of ACs in the autoclave causes significant increase of oxygen functionalities at surface, including groups possessing acid properties, and consequently, increasing of adsorption capacities with respect to polar substances: water, ammonia and benzene.

Therefore, this method allows to change porous structure of carbons to a lesser extent and to modify their surface structure to a greater extent. Besides, hydrothermal modification of A2PS and SCN slightly reduces energetic heterogeneity of their surface.

Acknowledgements The authors are grateful European Community, Seventh Framework Programme (FP7/2007-2013), Marie Curie Inter- national Research Staff Exchange Scheme (grant No. 230790) and V.M.G. is grateful to the STCU (grant No. 4481) for financial support.

Open Access This article is distributed under the terms of the Creative Commons Attribution Noncommercial License which permits any noncommercial use, distribution, and reproduction in any medium, provided the original author(s) and source are credited.

\section{References}

Choma, J., Burakiewicz-Mortka, W., Jaroniec, M., Li, Z., Klinik, J.: Monitoring changes in surface and structural properties of porous carbons modified by different oxidizing agents. J. Colloid Interface Sci. 214, 438-446 (1999)

Do, D.D., Nguyen, C., Do, H.D.: Characterization of micromesoporous carbon media. Colloids Surf. A 187-188, 51-71 (2001)

Dubinin, M.M., Sierpinsky, V.V.: Isotherm equation for water vapor adsorption by microporous carbonaceous adsorbents. Carbon 19, 402-403 (1981)

Gil, A., de la Puente, G., Grande, P.: Evidence of textural modifications of an activated carbon on liquid-phase oxidation treatments. Microporous Mater. 12, 51-61 (1997)

Gregg, S.J., Sing, K.S.W.: Adsorption, Surface Area and Porosity. Academic Press, London (1982)

Gun'ko, V.: Heterogeneity of adsorption energy of water, methanol and diethyl ether on activated carbons. Adsorption 11, 97-102 (2005)

Gun'ko, V.M., Mikhalovsky, S.V.: Evaluation of slitlike porosity of carbon adsorbents. Carbon 42, 843-849 (2004)

Fenelonov, V.B.: Porous Carbon. Nauka, Novosibirsk (1995) 
Jankowska, H., Świątkowski, A., Choma, J.: Active Carbon. Ellis Harwood, New York (1991a)

Jankowska, H., Świątkowski, A., Starostin, L., Lavrienko-Omecynska, J.: Adsorption of Ions on Active Carbon. PWN, Warsaw (1991b)

Leboda, R., Turov, V.V., Tomaszewski, W., Gun'ko, V.M., Skubiszewska-Zięba, J.: Effect of adsorption of nitroaromatic compounds on the characteristics of bound water layers in aqueous suspensions of activated carbons. Carbon 40, 389-396 (2002)

Marsh, H., Heinz, E.A., Rodriguez-Reinoso, F.: Introduction to Carbon Technologies. University of Alicante, Alicante (1997)

Matsumura, Y., Xu, X., Antal, M.J.: Gasification characteristics of an activated carbon in supercritical water. Carbon 35, 819-824 (1997)

Moreno-Castilla, C., Ferro-Gracia, M.A., Joly, J.P., Bautista-Toledo, I., Carrasco-Marin, F., Rivera-Utrilla, J.: Activated carbon surface modifications by nitric acid, hydrogen peroxide, and ammonium peroxydisulfate treatments. Langmuir 11, 4386-4392 (1995)

Nieh, G.-K., Grow, D.T.: Activation of carbon fibers by steam. J. Colloid. Interface Sci. 119, 280-285 (1987)

Platzer, B., Maurer, G.: A generalized equation of state for pure polar and nonpolar fluids. Fluid Phase Equilib. 51, 223-236 (1989)

Platzer, B., Maurer, G.: Application of a generalized Bender equation of state to the description of vapour-liquid equilibria in binary systems. Fluid Phase Equilib. 84, 79-110 (1993)

Rodriguez-Reinoso, F., Molina-Sabio, M., Munecas, M.A.: Effect of microporosity and oxygen surface groups of activated carbon in the adsorption of molecules of different polarity. J. Phys. Chem. 96, 2707-2713 (1992)

Salame, I.I., Bagreev, A., Bandosz, T.J.: Revisiting the effect of surface chemistry on adsorption of water on activated carbons. J. Phys. Chem. B 103, 3877-3884 (1999)

Salame, I.I., Bandosz, T.J.: Experimental study of water adsorption on activated carbons. Langmuir 15, 587-593 (1999)

Seredych, M., Bandosz, T.J.: Removal of ammonia by graphite oxide via its intercalation and reactive adsorption. Carbon 45, 21302132 (2007a)

Seredych, M., Bandosz, T.J.: The mechanism of ammonia retention on graphite oxides: role of surface chemistry and structure. J. Phys. Chem. C 111, 15596-15604 (2007b)

Sing, K.S.W., Everett, D.H., Haul, R.A., Moscou, L., Pieriotti, R.A., Rouquerol, J., Siemieniewska, T.: Reporting physisorption data for gas/solid systems with special reference to the determination of surface area and porosity (Recommendations 1984). Pure Appl. Chem. 57, 603-620 (1985)

Tarkovskaya, I.A.: Oxidized Carbon. Naukova Dumka, Kyiv (1981)

Tomaszewski, W., Gun'ko, V.M., Leboda, R., Skubiszewska-Zięba, J.: Interaction of amphetamine and its $\mathrm{N}$-alkyl-substituted derivatives with micro- and mesoporous adsorbents in polar liquids. J. Colloid Interface Sci. 282, 261-269 (2005)

Turov, V.V., Gun'ko, V.M., Leboda, R., Bandosz, T.J., SkubiszewskaZieba, J., Palijczuk, D., Tomaszewski, W., Zietek, S.: Influence of Organics on the Structure of Water Adsorbed on Activated Carbons. J. Colloid. Interface Sci. 253, 23-34 (2002) 